\title{
ESTUDO CINÉTICO DA REMOÇÃO DO CORANTE VERMELHO 4B POR DOLOMITA TERMICAMENTE MODIFICADA.
}

\author{
R. L. C. BANDEIRA ${ }^{1}$, A. A. da SILVA ${ }^{1}$, T. F. OLIVEIRA ${ }^{1}$, K.K. P. GOMES ${ }^{1}$ e M. L. P. da \\ SILVA $^{1}$ \\ ${ }^{1}$ Universidade Federal Rural do Semi-Árido, Departamento de Agrotecnologia e Ciências \\ Sociais \\ E-mail para contato: martaligia@ufersa.edu.br
}

\begin{abstract}
RESUMO - O impacto ambiental provocado pelo setor têxtil, através da geração de efluentes líquidos, aumenta de acordo com as necessidades exigidas pelas indústrias, crescendo a demanda de corantes têxteis utilizadas nos processos industriais, produzindo cada vez mais efluentes sem tratamentos e danos ambientais. Pois os corantes têxteis apresentam um alto grau de toxicidade e a sua grande maioria é considerada carcinogênico. Este estudo teve como objetivo realizar um estudo cinético do processo de remoção de cor de efluente têxtil modelo, contendo corante reativo vermelho 4B, utilizando como adsorvente a dolomita tratada termicamente, cedida pela Armil Mineradora do Nordeste. Os resultados do monitoramento cinético mostraram que o material em questão é altamente eficiente para a remoção do corante, visto que em apenas 30 segundos apresentou aproximadamente $90 \%$ de remoção e o processo de remoção do corante pela dolomita segue uma cinética de pseudo-segunda ordem.
\end{abstract}

\section{INTRODUÇÃO}

A indústria têxtil representa um importante setor da economia tanto no Brasil como no resto do mundo. O considerável crescimento verificado nos últimos anos trouxe como consequência uma maior emissão destas águas residuais ao meio ambiente (GUARATINI; ZANONI, 2000). Estes efluentes são altamente problemáticos, já que apresentam uma variedade de poluentes tóxicos. Devido a isto, o tratamento de seus efluentes constitui um sério problema o qual tem sido tema de pesquisa durante os últimos anos. Ambientalmente, a remoção da cor dos efluentes é um dos grandes problemas apresentado por esse setor. A elevada estabilidade biológica destes produtos dificulta seu tratamento por via convencional (DALLAGO et al., 2005; DEBRASSI et al., 2011). Diferentes tipos de tratamentos, tais como oxidação química, coagulação, floculação, precipitação química, nano filtração por membranas, troca iônica e adsorção, vêm sendo utilizados para tratar efluentes contendo corantes. Dentre estes, o processo físico de adsorção tem se mostrado bastante promissor na etapa de remoção de cor de efluentes líquidos industriais, utilizando diversos materiais adsorventes.

A teoria da adsorção baseia-se na separação de componentes de uma mistura, tendo a 


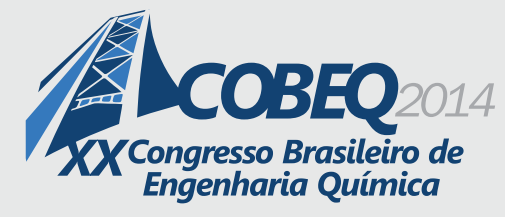

19 a 22 de outubro de 2014

Florianópolis/SC

transferência de massa como fenômeno físico. Na mistura, há um composto que está diluído na fase fluida, e um sólido, o adsorvente. Quando estas duas fases entram em contato, o composto ou íon que está diluído se difunde indo da fase fluida para a superfície do adsorvente. A força motriz desta difusão é a diferença de concentração entre a solução e a superfície do material sólido. (RUTHVEN, 1984.).

O mecanismo de adsorção pode ser descrito, basicamente, por três etapas consecutivas. Na primeira etapa, ocorre a transferência de massa externa do adsorvato em solução para a superfície do adsorvente; na segunda etapa, ocorre a difusão do adsorvato para os sítios de adsorção no interior do adsorvente; na terceira etapa acontece a adsorção propriamente dita. As etapas de transferência de massa externa e de difusão do adsorvato são as determinantes na velocidade de adsorção, enquanto que a última etapa não oferece nenhuma resistência ao processo. A transferência de massa ocorre em alguns minutos, mas a difusão do adsorvato pode levar algumas horas, constituindo o fator principal no que se refere ao tempo gasto no processo de adsorção, devido à estrutura interna altamente desenvolvida do adsorvente, com uma complexa estrutura reticular de poros e canais recobrindo inteiramente a partícula (McKAY, 1996).

Nos últimos anos, a adsorção vem sendo aceita como um dos processos mais apropriados para a purificação de água e de descartes aquosos. A cinética descreve a velocidade de remoção do soluto da solução que, por sua vez, controla o tempo de residência para a acumulação do adsorbato na interface sólido-líquido. Isso é importante para prever a velocidade com que o poluente é removido da solução aquosa, visando o desenvolvimento de sistemas adequados de tratamento (Ho e McKay, 1999).

Os modelos cinéticos são representados por equações matemáticas usadas para descrever o perfil de adsorção de solutos por sólidos, o que permite conhecer mais sobre o processo de adsorção. Embora os estudos de equilíbrio sejam importantes na determinação da eficácia do processo de adsorção, é necessário relacionar o efeito do tempo nas interações entre adsorvente e adsorvato, através de estudos de cinética de adsorção (Sparks, 1989 e Khraished, 2002). Estes estudos têm por objetivo a correlação matemática de dados experimentais, visando estabelecer hipóteses sobre os fatores determinantes da velocidade de adsorção e elucidar os mecanismos de adsorção envolvidos.

Dolomita é uma rocha mineral que pode ser encontrada em vários leitos sedimentares, ela também é encontrada em rochas metamórficas, mármores, veias hidrotermais e depósitos de substituição. Dolomita é tanto um mineral como uma pedra. A fórmula geral do grupo é $\mathrm{AB}\left(\mathrm{CO}_{3}\right)_{2}$, em que A pode ser tanto de cálcio, bário ou estrôncio e o B pode ser um ferro, magnésio, zinco ou manganês. A quantidade de cálcio e magnésio na maioria dos espécimes é igual, mas ocasionalmente um elemento pode ter uma presença ligeiramente maior do que o outro. Pequenas quantidades de ferro e manganês são por vezes, também presente. (Walker et al 2002). Devido às suas características como dureza elevada e densidade, dolomita é amplamente utilizada na fabricação de vidro, cerâmica, siderurgia, agricultura, controle de obras e construção.

Por ser abundante e apresentar baixo custo a dolomita será utilizada como adsorvente na remoção do corante reativo vermelho $4 \mathrm{~B}$ de um efluente modelo, objetivando verificar a viabilidade $\mathrm{e}$ a cinética do processo de remoção. 


\section{METODOLOGIA}

A dolomita $\mathrm{CaMg}\left(\mathrm{CO}_{3}\right)_{2}$ utilizada foi Cedida pela Armil Mineradora do Nordeste e já veio em forma de pó. Previamente a dolomita foi submetida a tratamento térmico a $800{ }^{\circ} \mathrm{C} \mathrm{em}$ forno mufla por um período de 8 horas, este processo leva em consideração que o componente de carbonato de magnésio da dolomita se decompõe a temperaturas próximas de $800^{\circ} \mathrm{C}$.

A solução estoque foi preparada pela dissolução do corante em água destilada, obtendo assim uma solução com concentração de $1000 \mathrm{mg} / \mathrm{L}$. A solução de trabalho do corante foi obtida mediante a diluição da solução estoque, apresentado uma nova concentração de $50 \mathrm{mg} / \mathrm{L}$. Partindo da solução de $50 \mathrm{mg} / \mathrm{L}$, foram feitas diluições sucessivas para obter concentrações de 10, 20, 30 e $40 \mathrm{mg} / \mathrm{L}$ utilizadas para a determinação da curva de calibração.

A determinação da concentração do corante nas amostras foi realizada por espectroscopia no ultravioleta/visível (UV/Vis), utilizando o Espectrofotômetro GEHAKA Modelo UV/Vis-340G. Após a obtenção do comprimento de onda para a solução de trabalho $(542 \mathrm{~nm})$ foi obtida a curva de calibração e a solução inicial foi analisada para se conhecer sua concentração inicial.

Para a execução do ensaio cinético, foi utilizada a proporção de $1 \mathrm{~g}$ de dolomita modificada/100 $\mathrm{mL}$ de solução de corante $(50 \mathrm{mg} / \mathrm{L})$, colocados em um shaker Modelo TE-420 da Tecnal na temperatura de $28{ }^{\circ} \mathrm{C}$ sob agitação de $180 \mathrm{rpm}$. Foram retiradas alíquotas da solução, filtradas e centrifugadas nos intervalos de tempo de 0,$5 ; 1 ; 3 ; 6 ; 10 ; 15 ; 20 ; 30$ e 60 minutos respectivamente. As soluções foram analisadas no espectrofotômetro, com o objetivo de se obter a concentração final das mesmas.

De posse das concentrações iniciais e finais a capacidade de remoção $\left(q_{e q}\right)$ foi calculada segundo a equação 1 :

$$
q_{e q}=\frac{V}{m}\left(C_{0}-C_{e q}\right)
$$

A predição da taxa de adsorção fornece importantes informações para a seleção das condições de operação ótimas em processos em batelada de grande escala. Para investigar o mecanismo da cinética de adsorção utilizamos os modelos pseudo-primeira-ordem, pseudo-segunda-ordem e difusão intra-partícula.

O modelo pseudo-primeira-ordem desenvolvida por Lagergren em 1898, interpreta os dados obtidos nos experimentos em banho finito, na forma linearizada, é descrito pela equação 2 a seguir:

$$
\frac{1}{\left(q_{e q}-q_{t}\right)}=\frac{1}{q_{e q}}+K_{1} \cdot t
$$


Onde: $\mathrm{t}$ é o tempo (min), $\mathrm{K}_{1}$ é a constante de velocidade de primeira ordem $((\mathrm{g} / \mathrm{mg}) / \mathrm{min}), \mathrm{q}_{\mathrm{t}}$ é a quantidade de corante adsorvida em qualquer tempo $(\mathrm{mg} / \mathrm{g})$ e $\mathrm{q}_{\mathrm{eq}}$ é a quantidade de corante adsorvida no equilíbrio $(\mathrm{mg} / \mathrm{g})$.

O modelo pseudo-segunda-ordem, desenvolvido por Ho e Mackay (Ho e McKay, 1998), para interpretar os dados obtidos nos experimentos em banho finito utiliza a equação linearizada 3 :

$$
\frac{\mathrm{t}}{\mathrm{qt}}=\frac{1}{\mathrm{k}\left(\mathrm{q}_{\mathrm{eq}}\right)^{2}}+\frac{1}{\mathrm{qeq}} \cdot \mathrm{t}
$$

Onde: $\mathrm{t}$ é o tempo (min), $\mathrm{k}$ é a constante de velocidade de primeira ordem $\left(\left(\mathrm{g} / \mathrm{mg}^{*} \mathrm{~min}\right), \mathrm{q}_{\mathrm{t}}\right.$ é a quantidade de corante adsorvida em qualquer tempo $(\mathrm{mg} / \mathrm{g})$ e $\mathrm{q}_{\mathrm{eq}}$ é a quantidade de corante adsorvida no equilíbrio $(\mathrm{mg} / \mathrm{g})$.

O modelo de difusão intrapartícula é um modelo cinético que apresenta a difusão interna como etapa determinante da taxa de adsorção, que é derivado segundo a lei de Fick. Para interpretar os dados obtidos nos experimentos em banho finito utiliza a equação 4 :

$$
C=C o-K_{d} \cdot t^{0,5}
$$

\section{RESULTADOS}

O efeito do tempo de contato na remoção do corante vermelho da solução é dado na Figura 1. A adsorção ocorre rapidamente no início do contato com o adsovente, provavelmente devido à grande quantidade de sítios ativos disponíveis. A partir dos 20 primeiros minutos de processo verifica-se uma pequena variação na adsorção o que indica a condição de equilíbrio, sendo o mesmo atingido com a total remoção do corante com 1 hora de contato entre as fases.

Na figura 2 pode-se observar a capacidade de remoção de corante pela dolomita modificada termicamente. Logo nos primeiros 30 segundos de contato o processo já exibe uma elevada capacidade de remoção, não sendo possível avaliar pelo gráfico a máxima capacidade de remoção exibida pelo adsorvente em estudo devido ao fato de o equilíbrio ter sido atingido em função da total remoção do corante da solução e não pela exaustação do adsorvente. 


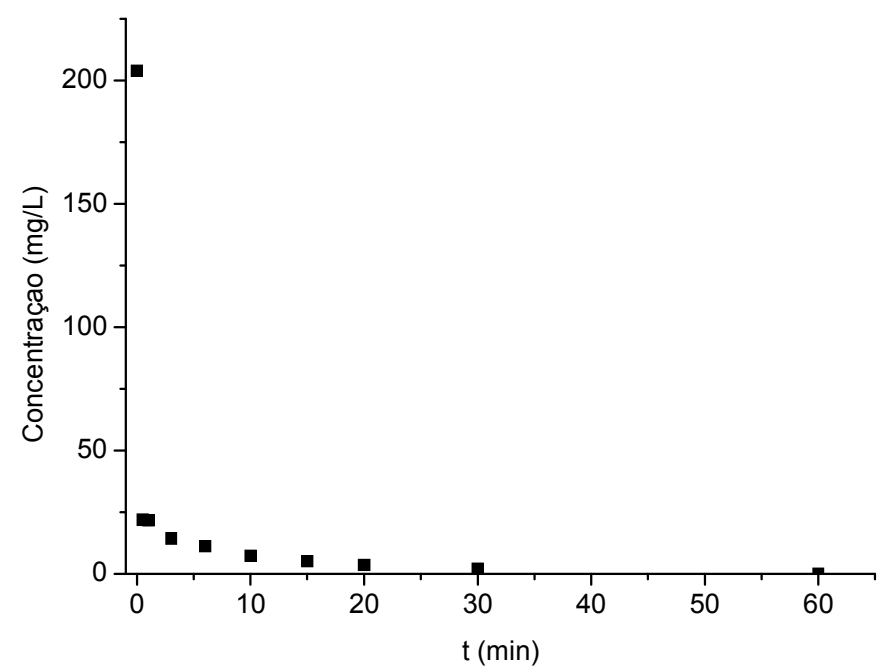

Figura 1 - Cinética de adsorção do corante vermelho 4B para a dolomita calcinada a $800^{\circ} \mathrm{C}$.

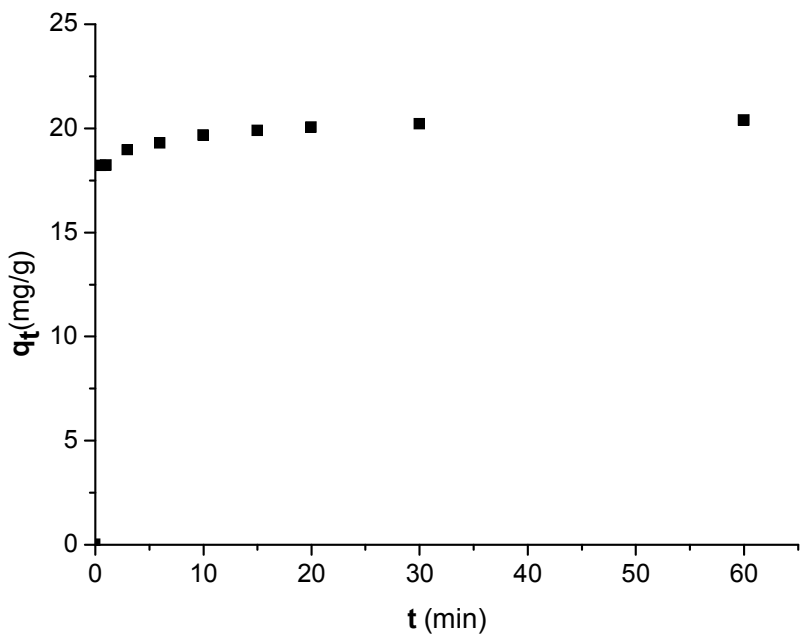

Figura 2 - Capacidade de adsorção do corante vermelho 4B pela dolomita calcinada a $800^{\circ} \mathrm{C}$.

A Figura 3 apresenta a forma linearizada do modelo de pseudo-primeira-ordem. Para representar a cinética do processo através do gráfico linearizado os dados devem apresentar um coeficiente de correlação próximo de 1 , pois o modelo deve explicar cerca de $100 \%$ dos dados. 
Como pode ser visto na Figura 3, o coeficiente de correlação foi de $\mathrm{R}^{2}=0,96302$ apontando um ajuste razoável para a adsorção do corante vermelho pela dolomita, porém não explica bem a cinética do processo, que não é de pseudo-primeira-ordem.

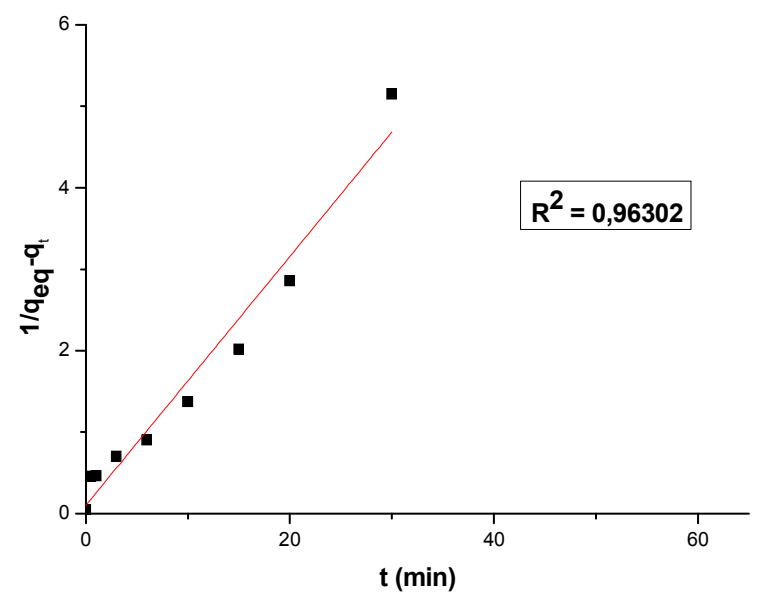

Figura 3 - Ajuste dos dados pelo modelo cinético de pseudo primeira ordem.

A Figura 4 apresenta os dados da cinética da adsorção ajustados pelo modelo linearizado de pseudo-segunda-ordem.

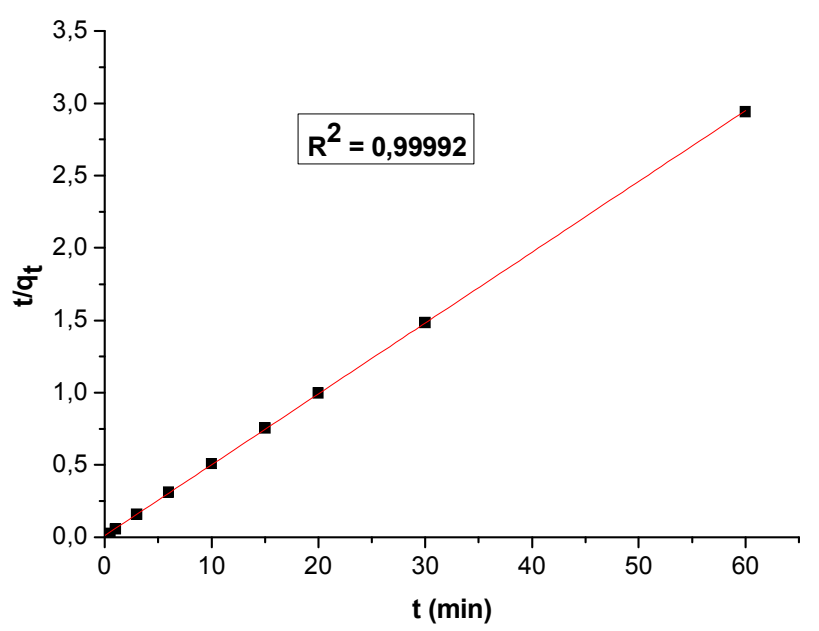

Figura 4 - Ajuste dos dados pelo modelo cinético de pseudo segunda ordem. 
Observa-se através da Figura 4, que o coeficiente de correlação foi de $R^{2}=0,99992$ sugerindo que o processo de remoção do corante vermelho 4B pela dolomita termicamente modificada segue o modelo de pseudo-segunda-ordem, uma vez que apresenta uma excelente correlação para o ajuste dos dados pelo modelo, explicando cerca de $100 \%$ dos dados.

A figura 5 mostra o ajuste dos dados pelo modelo da difusão intra-partícula.

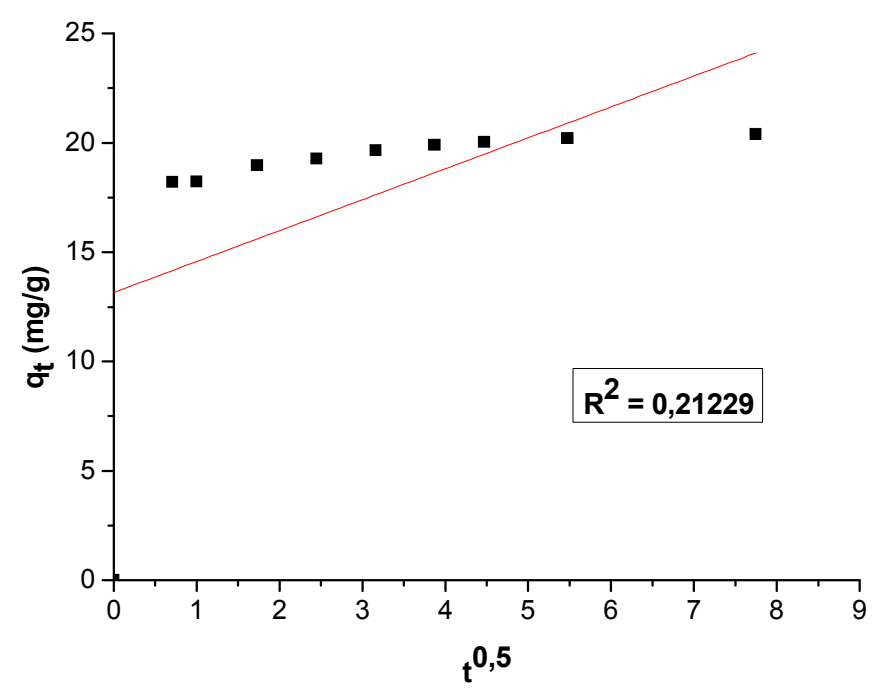

Figura 5 - Ajuste dos dados pelo modelo cinético da difusão intra-partícula.

Observa-se que os dados não se ajustam ao modelo proposto, e que, portanto o processo de remoção não é controlado pela difusão. Isto pode ser confirmado através do coeficiente de correlação obtido que foi de $\mathrm{R}^{2}=0,21229$.

Após avaliar o ajuste dos dados pelos principais mecanismos cinéticos que ocorrem nos processos de adsorção verificou-se que o processo em estudo se dá conforme o modelo de pseudosegunda-ordem, permitindo a obtenção do valor da constante de velocidade, que é mostrado na Tabela 1. A constante indica o quanto de corante é removido por quantidade de massa de adsorvente por tempo.

Tabela 1 - Parâmetros cinéticos da equação de pseudo-segunda-ordem para adsorção do corante vermelho $4 \mathrm{~B}$ por dolomita termicamente modificada.

\begin{tabular}{cc}
\hline $\mathrm{k}((\mathrm{g} / \mathrm{mg} * \min )$ & $\mathrm{R}^{2}$ \\
\hline 0,21554 & 0,99992
\end{tabular}




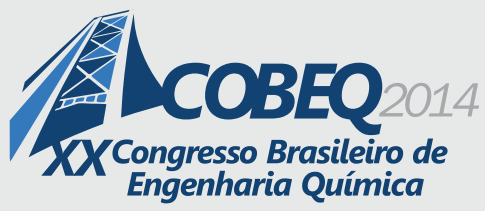

\section{CONCLUSÃO}

Visou-se com este estudo avaliar o potencial da dolomita modificada como adsorvente no tratamento da solução modelo contendo o corante reativo bifuncional 4B. Quando submetida ao tratamento térmico a dolomita se decompõe, tendo sua estrutura parcialmente destruída, indicando mudanças em sua composição química e de superfície e na porosidade do mineral, favorecendo o potencial de remoção de corantes reativos. O potencial da dolomita termicamente modificada de remoção do corante atingiu, em pouco tempo, o máximo que é de $100 \%$, apontando este material como altamente promissor como adsorvente do corante reativo vermelho $4 \mathrm{~B}$, pois além da eficiência no processo é um material abundante e de baixo custo, e o processo de calcinação apesar do gasto energético se dá de forma simples e em uma única etapa.

Com relação ao mecanismo cinético do processo comprovou-se que o mesmo apresenta um mecanismo de pseudo-segunda ordem, com coeficiente de correlação $\mathrm{r}^{2}=0,99992, \mathrm{q}_{\mathrm{eq}}=20,3892$ e o valor da constante de velocidade de $\mathrm{k}=0,21554 \mathrm{k}((\mathrm{g} / \mathrm{mg}) / \mathrm{min})$.

\section{REFERÊNCIAS}

DAllaGO, R. M.; SMANiOTTO, A.; OliVEIRA, L. C. A. Resíduos sólidos de curtumes como adsorventes para a remoção de corantes em meio aquoso. Química Nova, v. 28, n. 3, p. 433-437, 2005.

DEBRASSI, A.; LARGURA, M. C. T.; RODRIGUES, C. A. Adsorção do corante vermelho congo por derivados da o-carboximetilquitosana hidrofobicamente modificados. Quím. Nova, São Paulo, v. 34, n. 5, 2011 .

GUARATINI, CLÁUDIA C. I.; ZANONI, MARIA VALNICE B. Corantes Têxteis. Araraquara - SP, n.1, p.1-8, 31 mar. 2000.

HO, Y. S.; McKay, G; Kinetic models for the sorption of dye from aqueous solution by wood, Trans. Inst. Chem. Eng. 1998 76B 183-191.

HO, Y.S.; MCKAY, G. Pseudo-second order model for sorption processes. Process Biochem, v. 34, n. 5, p. 451-456, 1999.

KHRAISHED, M.A.M. et al. Elucidation of controlling steps of reactive dye adsorption on activated carbon.Ind. Eng. Chem. Res., v. 41, n. 6, p. 1651-1657, 2002. Disponível em: http://pubs.acs.org/doi/abs/10.1021/ie000942c Acesso em: 25 nov. 2009. doi: 10.1021/ie000942c.

MCKAY, G. Use of Adsorbents for the removal of pollutants from wastewaters. CRC Press, Florida, USA, 1996.

RUTHVEN, D. M., Principals of Adsorption and Adsorption Processes, John Wiley \& Sons, p. 436, 1984.

SPARKS, D.L. Kinetics of Soil Chemical Processes. San Diego: Academic Press, 1989.

WALKER, G.M.; HANSEN, L.; HANNA, J.-A., ALLEN, S. J.. Kinetics of a reactive dye adsorption onto dolomitic sorbents. Water Research, Reino Unido, p. 2081-2089. 11 nov. 2002. 